Check for updates

Cite this: RSC Adv., 2021, 11, 19083

\section{Silyl-naphthalene endoperoxides as switchable sources of singlet oxygen for bactericidal activity $\dagger$}

\author{
Min Qu, ${ }^{\text {ab }}$ Nan $\mathrm{Wu}^{\mathrm{c}}$ Wanqing Jiang, ${ }^{\mathrm{c}}$ Lei Wang, ${ }^{\text {ab }}$ Mahinur S. Akkaya*c \\ and Engin U. Akkaya (D)*ab
}

Singlet oxygen is a short half-life cytotoxic agent which can be generated by chemical and photochemical methods. In order to make use of its antibacterial action at a selected location, it is desirable to have singlet oxygen in a relatively stable, "caged" structure, in the form of an endoperoxide. Here, the trimethylsilyl (TMS) group supplies the steric bulk, inhibiting the cycloreversion reaction to produce very little singlet oxygen under ambient conditions. However, when fluoride ions are added as tetrabutylammonium fluoride, very rapid removal of the TMS group takes place, followed by the unhindered cycloreversion, releasing singlet oxygen much faster. The bactericidal action on surfaces was demonstrated using $E$. coli, and imaged under fluorescence microscopy. Considering the issues related to emergence of antibiotic resistant bacterial strains, "on demand singlet oxygen" appears to be an exciting alternative.
Received 15th April 2021 Accepted 20th May 2021

DOI: 10.1039/d1ra02933a

rsc.li/rsc-advances oxygen release rate is significantly slowed down. If this block can be removed by the modulators mentioned above in a fast process (chemical or photochemical) singlet oxygen release could be effectively controlled in both space and time.

Among the reactive oxygen species (ROS), singlet oxygen is the most reactive and short-lived. ${ }^{\mathbf{1}}$ In aqueous solutions, the half-life of singlet oxygen is about 3.5 microseconds. ${ }^{2}$ As a result of its reactivity, it can react with lipids, amino acids, nucleic acids and most of the cellular components. ${ }^{3}$ Non-specific reactivity demands a tight spatiotemporal control of its generation, if this reactivity is to be harnessed in a cytotoxic or antibacterial agent. In the last few decades, photodynamic antibacterial activity has attracted attention, ${ }^{4}$ since the bactericidal effect of singlet oxygen, is not subject to limitations of ordinary anti-bacterial agents, such as bacterial antibiotic resistance. It is also important to note that, ROS and specifically singlet oxygen is believed to be ultimate cause of bactericidal action of most antibiotics, if not all. ${ }^{5}$ We propose that the chemical (non-photonic) generation of singlet oxygen could extend the applicability of singlet oxygen as an effective antibacterial agent.

In recent years, we have provided evidence that singlet oxygen release reaction rate can be controlled by exogenic and endogenic (biological) modulators. ${ }^{6}$ Various naphthalene endoperoxide cycloreversion rates ${ }^{7}$ which were studied in more detail than other endoperoxide reactions, ${ }^{8}$ were shown by us ${ }^{6 b, c}$ and others ${ }^{9}$ to be highly sensitive to steric crowding near the endoperoxide bridge. When sterically crowded, the singlet

${ }^{a}$ State Key Laboratory of Fine Chemicals, Dalian University of Technology, 2 Linggong Road, 116024, Dalian, China.E-mail: eua@dlut.edu.cn

${ }^{b}$ Department of Pharmaceutical Sciences, Dalian University of Technology, 2 Linggong Road, 116024, Dalian, China.E-mail: leiwang@dlut.edu.cn

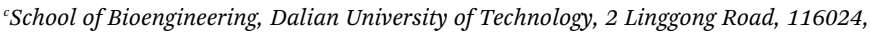
Dalian, China.E-mail:msa@dlut.edu.cn

$\dagger$ Electronic supplementary information (ESI) available. See DOI: 10.1039/d1ra02933a

\section{Experimental}

\section{Materials and instrumentation}

All commercial chemicals were used as supplied unless otherwise indicated. Anhydrous solvents were obtained from a Solvent Purification System. Column chromatography was performed using silica gel (200-300 mesh). ${ }^{1} \mathrm{H}$ and ${ }^{13} \mathrm{C}$ NMR spectra were recorded on Bruker Avance II $400 \mathrm{MHz}$ or Bruker Avance III $500 \mathrm{MHz}$. Signal splitting patterns were described as singlet $(\mathrm{s})$, doublet $(\mathrm{d})$, triplet $(\mathrm{t})$, quartet $(\mathrm{q})$ and multiplet $(\mathrm{m})$ with coupling constants $(J)$ in hertz $(\mathrm{Hz})$. High resolution mass spectra (HRMS) were recorded with an Agilent mass spectrometer. Reactions were monitored by thin-layer chromatography using Merck TLC Silica gel 60 F254.

Synthesis of compound 2. 2-(2-Bromophenyl)- $\mathrm{N}$-methoxy- $\mathrm{N}$ methylacetamide: a mixture of 2-bromophenylacetic acid (1) (6.45 g, $30 \mathrm{mmol}), \mathrm{EDC} \cdot \mathrm{HCl}(6.9 \mathrm{~g}, 36 \mathrm{mmol})$, DMAP (0.37 g, 3 mmol), DIPEA (6.27 mL, $36 \mathrm{mmol})$, and $N, O$-dimethylhydroxylamine hydrochloride $(3.51 \mathrm{~g}, 36 \mathrm{mmol})$ in dichloromethane $(150 \mathrm{~mL})$ was stirred at room temperature for $12 \mathrm{~h}$. The reaction mixture was concentrated under vacuum, and the residue was diluted with ethyl acetate $(200 \mathrm{~mL})$. The organic layer was washed with saturated $\mathrm{NaHCO}_{3}(50 \mathrm{~mL} \times 2)$ and brine $(50 \mathrm{~mL}$ $\times 2$ ), dried over $\mathrm{Na}_{2} \mathrm{SO}_{4}$, and concentrated under vacuum. The crude product was purified by column chromatography $(15 \%$, EtOAc in $n$-hexane) to afford 2-(2-bromophenyl)- $N$-methoxy- $N$ methylacetamide (2) as a colorless oil. Yield: $7.4 \mathrm{~g}(95 \%) .{ }^{1} \mathrm{H}$ 
NMR (400 MHz, chloroform-d) $\delta 7.56$ (d, $J=7.8 \mathrm{~Hz}, 1 \mathrm{H}$ ), 7.31$7.22(\mathrm{~m}, 2 \mathrm{H}), 7.16-7.08(\mathrm{~m}, 1 \mathrm{H}), 3.93(\mathrm{~s}, 2 \mathrm{H}), 3.70(\mathrm{~s}, 3 \mathrm{H}), 3.22(\mathrm{~s}$, $3 \mathrm{H}) ;{ }^{13} \mathrm{C}$ NMR $\left(100 \mathrm{MHz}, \mathrm{CDCl}_{3}\right) \delta 171.2,135.1,132.6,131.5$, 128.6, 127.5, 125.1, 61.3, 39.6, 32.3.

Synthesis of compound 3. 2-(2-Bromophenyl)- $N$-methoxy- $N$ methylpropanamide: to a solution of 2-(2-bromophenyl)- $N$ methoxy- $N$-methylacetamide (2) $(5.16 \mathrm{~g}, 20 \mathrm{mmol})$ in anhydrous THF (50 mL) was added NaHMDS (1.0 M in hexane, $30 \mathrm{~mL}, 30$ $\mathrm{mmol})$ at $-78{ }^{\circ} \mathrm{C}$ via syringe under Ar atmosphere. After stirring for $30 \mathrm{~min}$, MeI (4.3 g, $60 \mathrm{mmol})$ was added at the same temperature. The reaction mixture was stirred at $-78^{\circ} \mathrm{C}$ for $1 \mathrm{~h}$ and $0{ }^{\circ} \mathrm{C}$ for additional $1 \mathrm{~h}$. The reaction mixture was quenched with saturated $\mathrm{NH}_{4} \mathrm{Cl}$ and extracted with ethyl acetate $(50 \mathrm{~mL} \times$ $3)$. The organic layer was washed with brine, dried over $\mathrm{MgSO}_{4}$, and concentrated under vacuum. The residue was purified by column chromatography (10-15\%, EtOAc in $n$-hexane) to afford 2-(2-bromophenyl)- $N$-methoxy- $N$-methylpropanamide (3) as a colorless oil. Yield: $4.95 \mathrm{~g}(90 \%) .{ }^{1} \mathrm{H}$ NMR $(400 \mathrm{MHz}$, chloroform-d) $\delta 7.56$ (dd, $J=8.0,1.3 \mathrm{~Hz}, 1 \mathrm{H}), 7.33(\mathrm{dd}, J=7.8$, $1.8 \mathrm{~Hz}, 1 \mathrm{H}), 7.26(\mathrm{td}, J=7.6,1.3 \mathrm{~Hz}, 1 \mathrm{H}), 7.08(\mathrm{td}, J=7.8,1.6 \mathrm{~Hz}$, $1 \mathrm{H}), 4.65-4.49(\mathrm{~m}, 1 \mathrm{H}), 3.41(\mathrm{~s}, 3 \mathrm{H}), 3.16(\mathrm{~s}, 3 \mathrm{H}), 1.38(\mathrm{~d}, J=$ $7.0 \mathrm{~Hz}, 3 \mathrm{H}) ;{ }^{13} \mathrm{C}$ NMR (100 MHz, $\left.\mathrm{CDCl}_{3}\right) \delta 173.9,140.4,131.8$, 127.2, 127.1, 126.9, 123.0, 60.0, 40.6, 31.4, 17.2.

Synthesis of compound 4. To a solution of 2-(2-bromophenyl)- $N$-methoxy- $N$-methylpropanamide (3) (4.9 g, $18 \mathrm{mmol})$ in dichloromethane $(50 \mathrm{~mL})$ was added a solution of DIBAL-H $(1.0 \mathrm{M}$ in cyclohexane, $27 \mathrm{~mL}, 27 \mathrm{mmol}$ ) at $78{ }^{\circ} \mathrm{C}$ via syringe under $\mathrm{Ar}$ atmosphere. The reaction solution was stirred at $78{ }^{\circ} \mathrm{C}$ for $1 \mathrm{~h}$ and quenched with $1.0 \mathrm{~N} \mathrm{HCl}$. The organic layer was washed with brine, dried over $\mathrm{MgSO}_{4}$, and concentrated under vacuum. The residue was purified by column chromatography (5\% EtOAc in $n$ hexane) to afford 2-(2-bromophenyl)propanal (4) as a colorless oil. Yield: $3.07 \mathrm{~g}$ (81\%). ${ }^{1} \mathrm{H}$ NMR (400 MHz, chloroform-d) $\delta 9.74$ (s, $1 \mathrm{H}), 7.64(\mathrm{dd}, J=8.0,1.3 \mathrm{~Hz}, 1 \mathrm{H}), 7.33(\mathrm{td}, J=7.6,1.3 \mathrm{~Hz}, 1 \mathrm{H}), 7.18$ $(\mathrm{td}, J=7.8,1.7 \mathrm{~Hz}, 1 \mathrm{H}), 7.12(\mathrm{dd}, J=7.7,1.7 \mathrm{~Hz}, 1 \mathrm{H}), 4.17$ (q, $J=$ $7.1 \mathrm{~Hz}, 1 \mathrm{H}), 1.43(\mathrm{~d}, J=7.1 \mathrm{~Hz}, 3 \mathrm{H}) ;{ }^{13} \mathrm{C} \mathrm{NMR}\left(100 \mathrm{MHz}, \mathrm{CDCl}_{3}\right)$ $\delta$ 199.1, 136.8, 132.3, 128.2, 128.0, 127.1, 124.1, 50.9, 13.0.

Synthesis of compound 5. Propyne $(0.52 \mathrm{~g}, 13 \mathrm{mmol})$ was placed in a dry argon-flushed, $200 \mathrm{~mL}$ round-bottomed flask equipped with a stirring bar and dissolved in dry $\mathrm{CH}_{2} \mathrm{Cl}_{2}(60$ $\mathrm{mL}$ ). Titanium tetrachloride (10 mmol, $10 \mathrm{~mL}$ of a $1.0 \mathrm{M} \mathrm{CH}_{2} \mathrm{Cl}_{2}$ solution) was added via a syringe at room temperature. Then, 2(2-bromophenyl)propanal (4) (2.13 g, $10 \mathrm{mmol})$ was added via a syringe at room temperature. The reaction mixture was allowed to stir for $4 \mathrm{~h}$ and then was hydrolyzed with water. The mixture was extracted into hexanes, and the organic layer separated, dried over anhydrous $\mathrm{MgSO}_{4}$, concentrated under reduced pressure, and purified by flash column chromatography to afford 5-bromo-1,4-dimethylnaphthalene (5) as a colorless liquid. Yield: $1.1 \mathrm{~g}(47 \%) .{ }^{1} \mathrm{H}$ NMR $(400 \mathrm{MHz}$, chloroform-d) $\delta 7.88(\mathrm{~d}, J=8.4 \mathrm{~Hz}, 1 \mathrm{H}), 7.76(\mathrm{~d}, J=7.4 \mathrm{~Hz}, 1 \mathrm{H})$, 7.15-7.19 (m, 2H), 7.12 (d, $J=7.2 \mathrm{~Hz}, 1 \mathrm{H}), 3.00(\mathrm{~s}, 3 \mathrm{H}), 2.54$ (s, $3 \mathrm{H}) ;{ }^{13} \mathrm{C}$ NMR $\left(100 \mathrm{MHz}, \mathrm{CDCl}_{3}\right) \delta$ 135.6, 133.5, 133.3, 133.2, 131.5, 130.6, 127.1, 125.4, 124.9, 120.7, 26.4, 20.4 .

Synthesis of compound 6. Magnesium turnings $(0.17 \mathrm{~g}, 7$ $\mathrm{mmol}$ ) was activated with catalytic amount of iodine in $5 \mathrm{~mL}$ of THF for 15 minutes with vigorous stirring under Ar atmosphere.
5-Bromo-1,4-dimethylnaphthalene (5) (0.71 g, $3 \mathrm{mmol})$ was added to the reaction mixture in ice-bath. Then, TMS-Cl $(0.38 \mathrm{~g}, 3.6$ mmol) was dissolved in $3.0 \mathrm{~mL}$ THF and was added to the reaction mixture dropwise. The reaction mixture was allowed to stir at room temperature for 18 hours. Then, the mixture was extracted with water and DCM for three times. After removal of the solvent by rotary evaporator, the crude product was purified by silica gel column chromatography with hexane : EtOAc (95:5, v/v) as the eluent to afford (5,8-dimethylnaphthalen-1-yl)trimethylsilane (6) as a colorless oil. Yield: $0.3 \mathrm{~g}$ (44\%). ${ }^{1} \mathrm{H}$ NMR (400 MHz, chloroform-d) $\delta 7.95(\mathrm{dd}, J=8.4,1.1 \mathrm{~Hz}, 1 \mathrm{H}), 7.81(\mathrm{dd}, J=6.9,1.0 \mathrm{~Hz}, 1 \mathrm{H}), 7.36-$ $7.31(\mathrm{~m}, 1 \mathrm{H}), 7.22-7.06(\mathrm{~m}, 2 \mathrm{H}), 2.75(\mathrm{~s}, 3 \mathrm{H}), 2.58(\mathrm{~s}, 3 \mathrm{H}), 0.38(\mathrm{~s}$, $9 \mathrm{H}) ;{ }^{13} \mathrm{C} \mathrm{NMR}\left(100 \mathrm{MHz}, \mathrm{CDCl}_{3}\right) \delta 136.9,136.1,134.6,132.58$, 132.5, 132.0, 127.4, 125.5, 125.1, 122.7, 23.5, 19.1, 2.5.

Synthesis of compound 7. (5,8-dimethylnaphthalen-1-yl) trimethylsilane (6) (0.3 g, $1.32 \mathrm{mmol})$ was dissolved in $10 \mathrm{~mL}$ DCM. The reaction mixture was cooled to $0{ }^{\circ} \mathrm{C}$ in the ice bath. Methylene blue $(0.04 \mathrm{~g}, 0.14 \mathrm{mmol})$ was added into the solution and mixture was stirred for 5 hours under oxygen atmosphere. During the reaction, $18 \mathrm{~W}, 630 \mathrm{~nm}$ red light was used. After removal of the solvent by rotary evaporator, the crude product was purified by silica gel column chromatography with hexane : EtOAc (95:5, v/v) as the eluent. The product 7 was obtained in colorless oil. Yield: $0.33 \mathrm{~g}(98 \%) .{ }^{1} \mathrm{H}$ NMR $(400 \mathrm{MHz}$, chloroform-d) $\delta 7.44$ (dd, $J=7.8,1.2 \mathrm{~Hz}, 1 \mathrm{H}), 7.29(\mathrm{dd}, J=7.4$, $1.2 \mathrm{~Hz}, 1 \mathrm{H}), 7.19-7.11(\mathrm{~m}, 1 \mathrm{H}), 6.61(\mathrm{~s}, 2 \mathrm{H}), 1.96$ (s, 3H), 1.78 (s, $3 \mathrm{H}), 0.35(\mathrm{~s}, 9 \mathrm{H}) ;^{13} \mathrm{C} \mathrm{NMR}\left(100 \mathrm{MHz}, \mathrm{CDCl}_{3}\right) \delta$ 147.1, 140.0, 139.2, 138.6, 133.2, 131.5, 124.6, 120.7, 80.4, 77.0, 18.5, 15.7, 1.9.

\section{Results and discussion}

Based on the reported effects of 5-methyl substitution (Fig. 1) on the cycloreversion rate of 1,4-dimethylnaphthalene endoperoxide $(1,4),{ }^{10}$ we targeted the compound 7 for synthesis. Previously, we synthesized its structural isomer where the steric hindrance is on $\mathrm{C}-2$, but steric block on the other side of the bridgehead substitution, may offer additional advantages in deprotection rates and/or stability of the initial endoperoxide. The synthesis (Fig. 2) of compound 7 makes use of an effective methodology $\mathbf{1 0}^{\mathbf{1 0}}$ which allows the preparation of substituted naphthalenes, starting from substituted phenylacetaldehyde (4, in this case) and the appropriate alkyne. Aldehyde itself can be obtained from the commercially available materials in just two steps. Once the naphthalene core $\mathbf{5}$ is constructed, the bulky trimethylsilyl (TMS) group is substituted via a Grignard reaction. Irradiation of compound 6 under oxygen atmosphere with methylene blue (MB) as a photosensitizer, and a red LED array
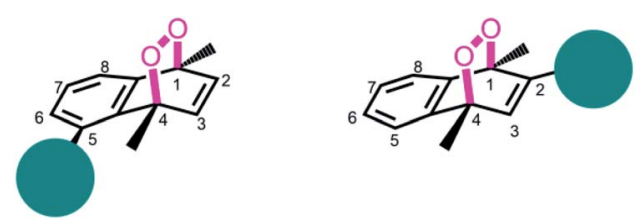

Fig. 1 Bulky substituents near the endoperoxide bridge is known to inhibit cycloreversion reaction rate. 


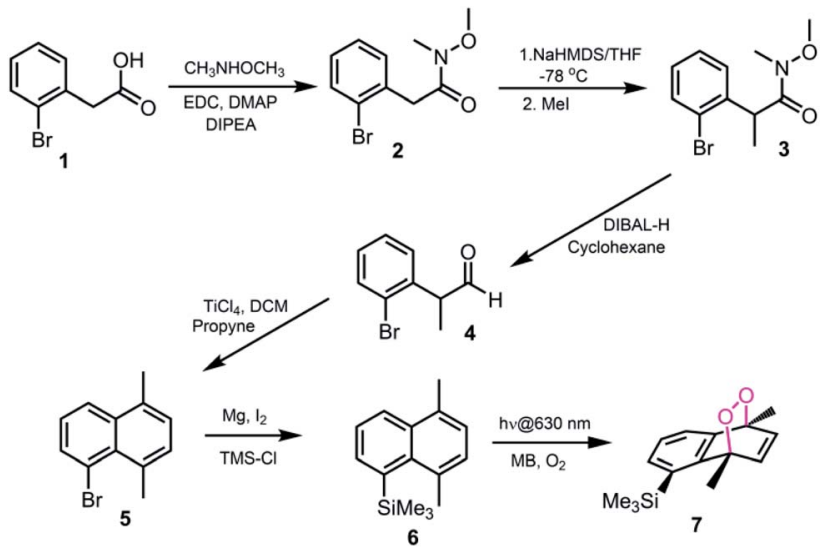

Fig. 2 The synthesis of 5-TMS-1,4-dimethylnaphthalene 6 and its corresponding endoperoxide 7 .

emitting at $630 \mathrm{~nm}$, gives the endoperoxide compound in high yields. Endoperoxide 7 can be separated from the reactant and any unreacted material from the previous step (compound 5) by silica gel column chromatography.

We studied cycloreversion rate of the compound 7 by ${ }^{1} \mathrm{H}$ NMR (Fig. 3). As expected, the TMS substituent at the 5 position slowed down the cycloreversion reaction. We were able to determine the half-life (ESI) as $125 \mathrm{~h}$ at $25^{\circ} \mathrm{C}$. Compared to the
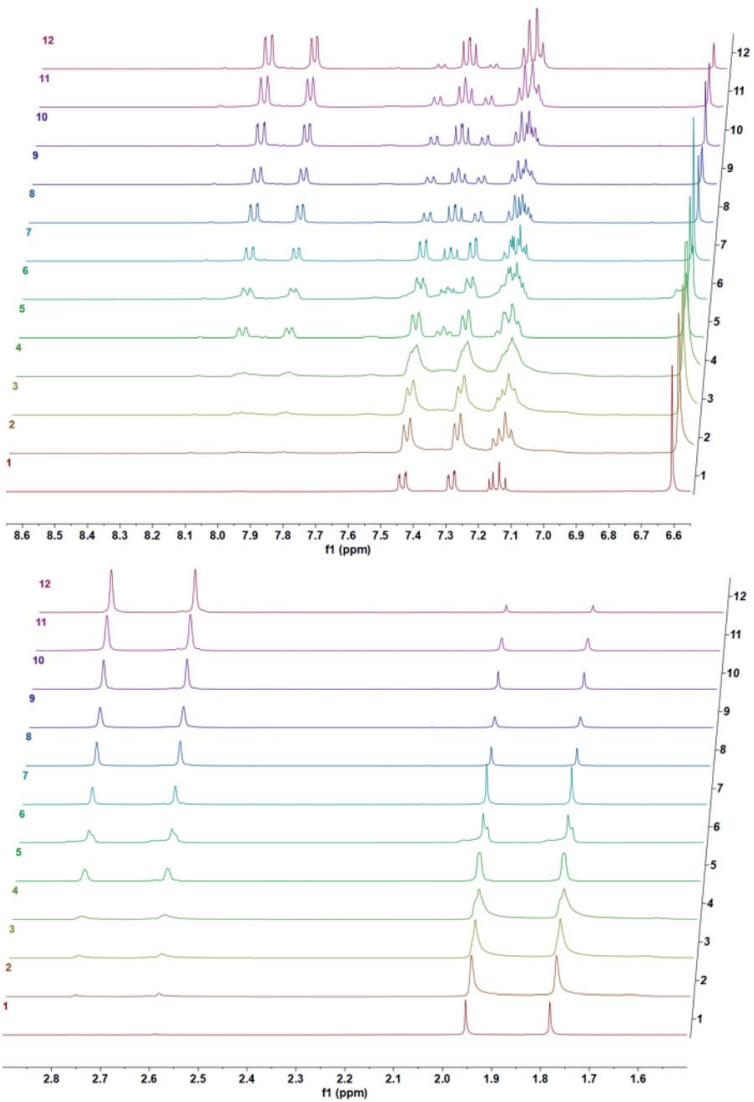

Fig. 3 Temporal evolution of ${ }^{1} \mathrm{H}$ NMR spectra of the endoperoxide 7 in $\mathrm{CDCl}_{3}$ at $37^{\circ} \mathrm{C}$. Top downfield region, bottom: upfield region of the spectra. From bottom to top: 0 h, 0.5 h, 1.5 h, 2.5 h, 5.5 h, 8 h, 10 h, 12 h, 24 h, 33 h, 52 h, 73 h.

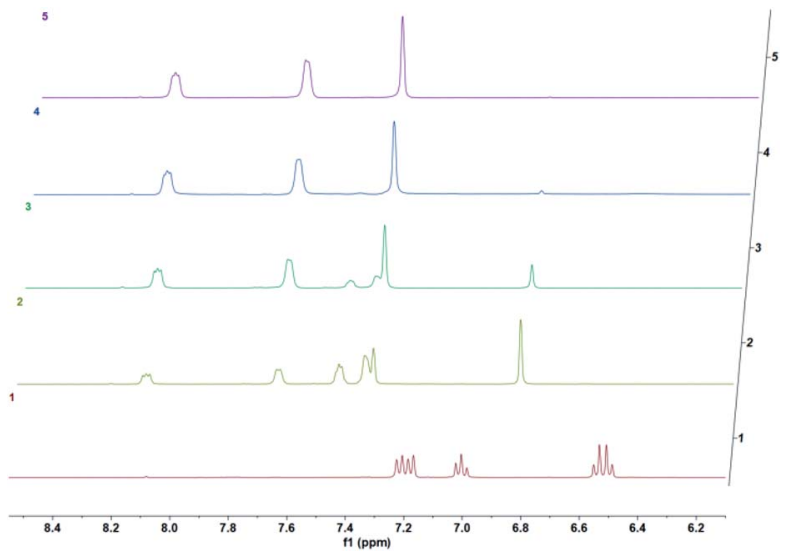

Fig. 4 Temporal evolution of ${ }^{1} \mathrm{H}$ NMR spectra of the endoperoxide 7 in DMSO $-d_{6}$ following the addition of TBAF after $t=0$ at $37^{\circ} \mathrm{C}$ in DMSO$d_{6}$ as the solvent. $0 \mathrm{~h}, 5 \mathrm{~min}, 1.5 \mathrm{~h}, 3.5 \mathrm{~h}, 5 \mathrm{~h}$. The conversion of 7 to 9 is complete in 5 minutes under these conditions.

unsubstituted 1,4-dimethylnaphthalene endoperoxide 11, the cycloreversion reaction rate is 25 times slower.

We then wanted to demonstrate that the addition of fluoride indeed results in a fast removal of the TMS-steric inhibitor group, which is followed by an accelerated cycloreversion. The ${ }^{1} \mathrm{H}$ NMR data shown in Fig. 4 clearly show these changes. The first $(t=0)$ NMR shows the typical protons of the endoperoxide 7 in the 8.4-6.2 ppm region. Immediately after the addition of TBAF in THF, TMS is removed completely within 5 min (spectrum 2). ${ }^{1} \mathrm{H}$ NMR data confirm the fact that removal of the TMS group is much faster than the cycloreversion reaction of the endoperoxide 7. Then the transformation of $\mathbf{9}$ to $\mathbf{1 1}$ takes place at a much faster rate. In order to confirm the identity and rate of the other product of cycloreversion, a solution of the endoperoxide 7 was prepared in DMSO, and the singlet oxygen probe 1,3-diphenyl-iso-benzofuran (DPBF) was added. As the reaction proceeds, cycloaddition of singlet oxygen initiates degradation of the benzofuran structure, and the absorbance peak at $414 \mathrm{~nm}$ due the benzofuran decreases (Fig. 5) as the singlet oxygen is

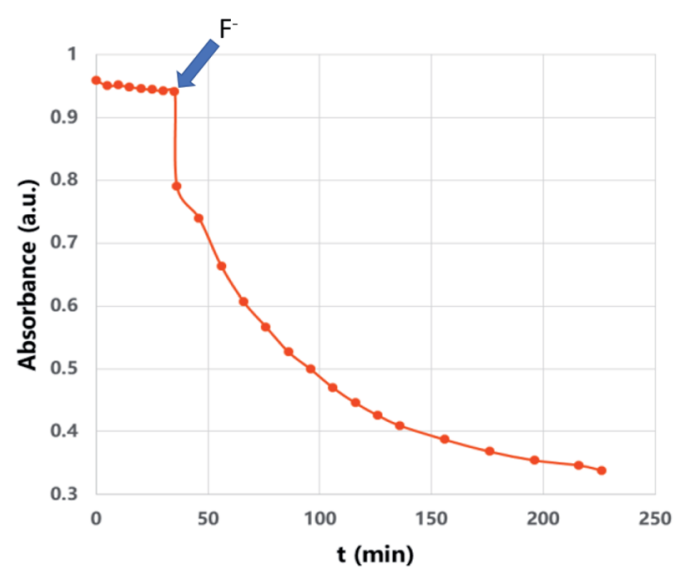

Fig. 5 "Off-On" switching of ${ }^{1} \mathrm{O}_{2}$ release: when fluoride $(6 \mathrm{mM})$ in the form of TBAF in THF was added, the trap (DPBF, $27 \mu \mathrm{M}$ ) absorbance in DMSO at $414 \mathrm{~nm}$ starts to decrease sharply in a pseudo-first order reaction, coupled to the cycloreversion of endoperoxide $7(200 \mu \mathrm{M})$. 
7

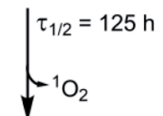<smiles>Cc1ccc(C)c2c(C)cccc12</smiles>

6

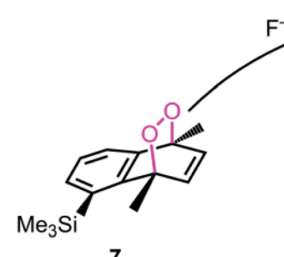

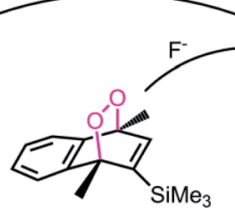

8

$\tau^{-1 / 2} \mathrm{O}_{2}=800 \mathrm{~h}$

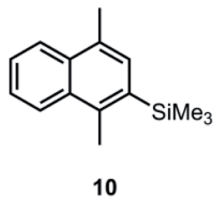

10

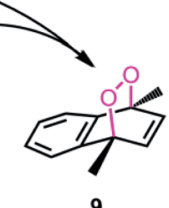

$\tau^{-1 / 2} \mathrm{O}_{2}$

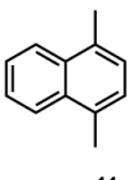

11
Fig. 6 Steric inhibition of cycloreversion as illustrated with compound 7 and selected endoperoxide derivatives from literature. ${ }^{6}$ The cycloreversion rates of 1,4-dimethylnaphthalene endoperoxides were determined at $25^{\circ} \mathrm{C}$. Steric bulk at positions 2 and 5 seem to be a significant stabilizing factor for the endoperoxide. The other product formed in all of the cycloreversion reactions is singlet oxygen $\left({ }^{1} \mathrm{O}_{2}\right)$.

produced. The reaction is highly specific to singlet oxygen. Clearly, fluoride addition causes a much accelerated release of singlet oxygen, which is due to the rapid "uncaging" of the endoperoxide. The general scheme of TMS-removal coupled acceleration of singlet oxygen release is presented in Fig. 6 . Finally, we wanted to demonstrate the antibacterial action of singlet oxygen generated by fluoride addition. For bacterial overnight culture, a single colony of $E$. coli (Dh5 $\alpha$ ) used to inoculate $2.0 \mathrm{~mL} \mathrm{LB}$ for $18 \mathrm{~h}$ at $37^{\circ} \mathrm{C}$ for constant shaking at $200 \mathrm{rpm}$. These cells were aliquoted into fresh tubes for endoperoxide $/ \mathrm{F}^{-}$and mock treatments. Varying concentrations (40 $\mathrm{mM}$ ) of endoperoxides 7 or 8 in DMSO and TBAF (100 mM) in DMSO were mixed at $1: 1(5 \mu \mathrm{M} / 5 \mu \mathrm{M})$ ratio, incubated for $30 \mathrm{~min}$ at RT for activation. Then $10 \mu \mathrm{L}$ of the reaction mixture was added directly into fresh tubes, onto which the cells in 90 $\mu \mathrm{L}$ were added, and incubated for 30 minutes. The treated and mock treated cells were collected by spinning and washed with $200 \mu \mathrm{L}$ phosphate-buffered saline (PBS) for two times. The cells were suspended and incubated in $20 \mu \mathrm{L}$ acridine orange/ ethidium bromide staining solution (prepared according to the manufacturer's instructions; BBI Life Sciences, Shanghai, PRC) in dark. The cells were collected by spinning and washed and suspended in $20 \mu \mathrm{L} 1 \times$ buffer of the staining kit. The samples were investigated under bright field, FTIC, and TxRED filters using fluorescent microscope. The pictures were taken with exposures of 100 milliseconds for brightfield and 500 milliseconds exposures with FITC and TxRED filters at $100 \times$ magnification. We compared the bactericidal activity of the isomeric endoperoxides 7 and 8 at $2.0 \mathrm{mM}$ concentration.

The ratio of the red channel total intensity (corresponding to dead cells) and the green channel total intensity (corresponding to live cells) is provided on the microscopy images (Fig. 7.). The microscopy data show that singlet oxygen generated by the action of fluoride on endoperoxide 7 has a demonstrable bactericidal effect, which significantly larger than endoperoxide

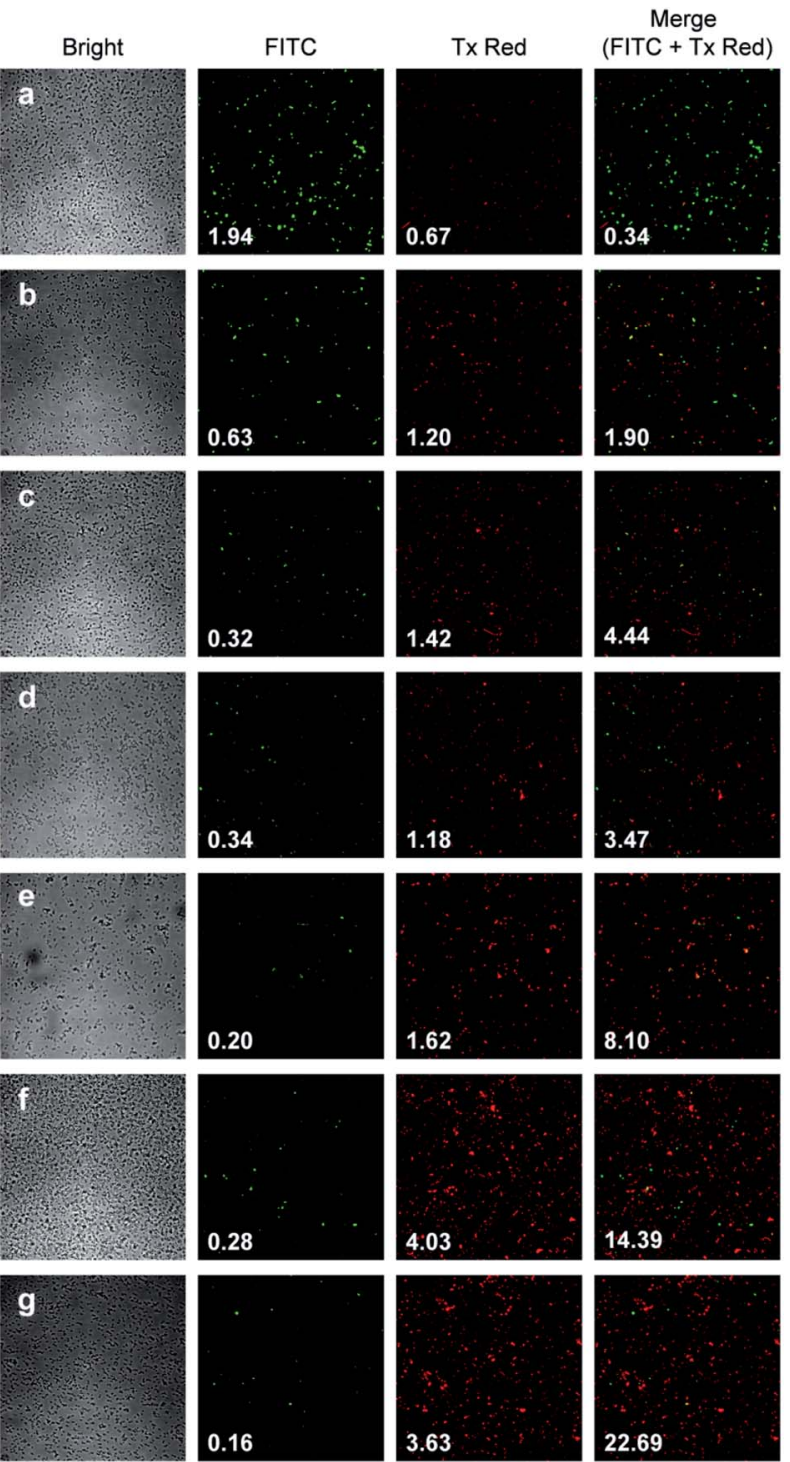

Fig. 7 Dead/live assay picture matrix of the action of endoperoxides 7 or 8 activated by TBAF on $E$. coli. Red emission intensity to green emission intensity ratios are indicated in each picture at the bottom left. These are the resulting after 30 minutes incubation followed by washing and staining. (a) control, (b) $10 \% \mathrm{v} / \mathrm{v}$ DMSO, (c) $10 \% \mathrm{v} / \mathrm{v} \mathrm{DMSO}$, $5 \mathrm{mM}$ TBAF; (d) $10 \% \mathrm{v} / \mathrm{v}$ DMSO, $2 \mathrm{mM}$ endoperoxide 8; (e) $10 \% \mathrm{v} / \mathrm{v}$ DMSO, $2 \mathrm{mM}$ endoperoxide 7; (f) 10\% v/v DMSO, $2 \mathrm{mM}$ endoperoxide 8, $5 \mathrm{mM}$ TBAF; (g) 10\% v/v DMSO, $2 \mathrm{mM}$ endoperoxide 7, $5 \mathrm{mM}$ TBAF. Column 1 from left: bright field images, Column 2: FITC filter, Column 3: TXRED filter, Column 4: merged. The numbers on the bottom left are total intensity in that filter range, except for the final column where it is the red to green ratio.

7 alone, and endoperoxide $\mathbf{8}+$ fluoride. The latter difference may be due to rate of TMS displacement.

\section{Conclusions}

In summary, we present a proof of principle for the use of caged singlet oxygen compounds as potential bactericidal agents activated by fluoride ions. The current work, while presenting a novel and interesting synthesis of a 5-TMS-substituted 
naphthalene endoperoxide, it also demonstrates the generality of steric hindrance via silyl functionalization. We provide a stable endoperoxide which could be transformed into an effective antibacterial agent on exposure to fluoride for 5 minutes. These properties of the endoperoxide compounds could make them potentially useful especially in dental antibacterial applications. Work in that direction is currently in progress in our laboratories.

\section{Conflicts of interest}

There are no conflicts to declare.

\section{Acknowledgements}

The authors acknowledge support from LiaoNing (China) Revitalization Talents Program XLYC1902001 (E. U. A), XLYC1907021 (L. W.), and the Fundamental Research Funds for the Central Universities DUT19RC(3)009 (L. W.), DUT18RC(3) 050 (M. S. A.).

\section{Notes and references}

1 M. E. Sosa Torres, J. P. Saucedo-Vázquez and P. M. Kroneck, "Chapter 1, Section 3, The Dark Side of Dioxygen", in Sustaining Life on Planet Earth: Metalloenzymes Mastering Dioxygen and Other Chewy Gases, Metal Ions in Life Sciences, ed. P. M. Kroneck and M. E. Torres, Springer, 2015, vol. 15, pp. 1-12.

2 (a) P. Ogilby, Photochem. Photobiol. Sci., 2010, 9, 1543-1560; (b) M. Bregnhøj, M. Westberg, F. Jensen and P. R. Ogilby, Phys. Chem. Chem. Phys., 2016, 18, 22946-22961.
3 P. Di Mascio, G. R. Martinez, S. Miyamoto, G. E. Ronsein, M. H. G. Medeiros and J. Cadet, Chem. Rev., 2019, 119, 2043-2086.

4 (a) Z. H. Yu, X. S. Li, F. G. Xu, X. L. Hu, J. T. Yan, N. Kwon, G. R. Chen, T. T. Tang, X. J. Dong, Y. Y. Mai, D. J. Chen, J. Yoon, X. P. He and H. Tian, Angew. Chem., Int. Ed., 2020, 59, 3658-3664; (b) H.-B. Cheng, X. S. Li, N. Kwon, Y. Fang, G. Baeka and J. Yoon, Chem. Commun., 2019, 55, 1231612319; (c) X. Li, H. T. Bai, Y. C. Yang, J. Yoon, S. Wang and X. Zhang, Adv. Mater., 2019, 31, 1805092.

5 F. Baquero and B. R. Levin, Nat. Rev. Microbiol., 2021, 19, 123-132.

6 (a) W. Fudickar and T. Linker, Angew. Chem., Int. Ed., 2018, 57, 12971-12975; (b) E. Ucar, D. Xi, O. Seven, C. Kaya, X. J. Peng, W. Sun and E. U. Akkaya, Chem. Commun., 2019, 55, 13808-13811; (c) S. Ayan, G. Gunaydin, N. YesilgulMehmetcik, M. E. Gedik, O. Seven and E. U. Akkaya, Chem. Commun., 2020, 56, 14793-14796.

7 M. Klapper and T. Linker, Chem.-Eur. J., 2015, 21, 85698577.

8 (a) S. Benz, S. Notzli, J. S. Siegel, D. Eberli and H. J. Jessen, J. Med. Chem., 2013, 56, 10171-10182; (b) M. Matsumoto, M. Yamada and N. Watanabe, Chem. Commun., 2005, 483485.

9 H. H. Wasserman, K. B. Wiberg, D. L. Larsen and J. Parr, J. Org. Chem., 2005, 70, 105-109.

10 G. W. Kabalka, Y. Ju and Z. Wu, J. Org. Chem., 2003, 68, 79157917. 